\title{
Commentary Underrepresented Minorities in Science: ACNP Strives to Increase Minority Representation and Inclusion
}

\author{
Carlos A Bolaños-Guzmán*,1 and Carlos A Zarate Jr $^{2}$ \\ 'Department of Psychology, Texas A\&M University, College Station, TX, USA; ${ }^{2}$ Experimental Therapeutics \& Pathophysiology Branch \& Section \\ of Neurobiology and Treatment of Mood Disorders, Division of Intramural Research Program, National Institute of Mental Health, Bethesda, \\ MD, USA
}

Neuropsychopharmacology (2016) 4I, 242 I-2423; doi: I 0. I 038/npp.20 I 6.7I

The need and importance for diversity in science, technology, engineering, and mathematics (STEM) have been recognized and documented for decades as a socioeconomic good. Broadly, diversity of thought is at the heart of successful scientific research. Modern science, by its nature, is largely collaborative and requires the pursuit of the best ideas generated by a team of people. In this context, diversity of thought, of background, and of experience leads to a wider pool of innovative hypotheses for scientists to draw from. Scientists in general pride themselves on their objectivity; nevertheless, point of view, background, and personal experience significantly contribute to what scientific questions are asked and how researchers go about answering them.

Depending on perspective and context, the term diversity can mean different things to different people. For instance, individuals from all over the world with a variety of backgrounds already engage in the scientific enterprise, bringing with them abundant cultural and philosophical inclinations. Within the context of this article, however, we use the term diversity to refer to the inclusion of women and minorities. Minorities, in turn, are defined as certain racial and ethnic groups such as African American, Latino, Native American and Pacific Islander-including people with disabilities and other disadvantaged backgrounds; such populations traditionally underrepresented in science fields. The purpose of this commentary is to give a broad overview of the state of diversification in science; more specifically, minority representation within the American College of Neuropsychopharmacology (ACNP), and on initiatives conducive to attracting, developing, and retaining these scientists within the ACNP.

From the outset, it should be noted that women and underrepresented minorities (URMs) are earning $\mathrm{PhDs}$ in science in greater numbers than ever before, reflecting the progress made from years of programmatic investment;

*Correspondence: Dr CA Bolaños-Guzmán, Department of Psychology, Texas A\&M University, 3245 TAMU, College Station, TX 77843, USA, Tel: 979-845-258I, Fax: 979-845-4727,

E-mail: bolanos-guzman@tamu.edu however, despite a national emphasis on diversification, both women and URMs often encounter significant, if not insurmountable, professional challenges, and today remain severely underrepresented in science and engineering (National Research Council, 2007, 2011; National Science Foundation, 2014). Furthermore, according to the National Science Foundation (NSF), women, and URM scientists and engineers are more likely to be unemployed (National Science Foundation, 2014). Indeed, recent reports demonstrate that in spite of notable increases in hiring activity in STEM fields since the year 2000, existing hiring practices have not benefited women and minorities (Neuhauser, 2015; Change the Equation, 2015). Instead, the gender and racial gap in science continues to widen, and our field is, for all intents and purposes, no more diverse now than it was almost two decades ago (Change the Equation, 2015; National Science Foundation, 2014; Neuhauser, 2015).

The National Institutes of Health (NIH) has stated that improving diversity in biomedical research is crucial (Tabak and Collins, 2011). However, although women now earn over half of PhDs in the biomedical sciences and in academic medicine, they represent a third of the tenured and tenuretrack faculty in biomedical sciences (Leadley et al, 2012), may receive less start-up funding than men (Sege et al, 2015), comprise $<20 \%$ of senior investigators at the $\mathrm{NIH}$ (Women Scientist Advisors, 2016), and their numbers in upper management and scientific advisory boards in the biotechnology (McCook, 2013) and pharmaceutical (Deman, 2012) industry are even less admirable. The picture is grimmer for racial/ethnic URMs, who make up only $2 \%$ of new tenure-track and tenured faculty at medical schools despite receiving $13 \%$ of $\mathrm{PhDs}$ in these fields; it is worth noting that these numbers are virtually unchanged from those reported in 1980 (Leadley et al, 2012; National Institutes of Health, 2012; National Science Foundation, 2015). Furthermore, women and URMs spend more time in lower academic ranks, are promoted at much lower rates, are paid less (compared with others in similar positions), are less likely to hold senior faculty and administrative positions, and receive $<5 \%$ of NIH R01 awards (Fang et al, 2000; Leadley 
et al, 2012; National Institutes of Health, 2012; Tabak and Collins, 2011). These obstacles may reflect a lack of effective networking opportunities, a lack of committed mentors, or differences in faculty responsibility-that is, women and URMs may be less likely to be given regular opportunities to distinguish themselves. All of these factors may ultimately make women and URMs less visible to key decision-makers (Rodriguez et al, 2014, 2015). Deplorably, the deck seems stacked even higher against women of color, as they are likely to face double disadvantage: that of being female and a racial/ethnic minority (Bernstein, 2015).

Recognizing the importance for increased diversity and inclusion, the ACNP implemented targeted initiativesincluding the formation of several Task Force groups-to better address issues related to inclusion and retention of women (see Moghaddam and Gur, 2015) and URMs, and to gauge progress. The Minority Task Force (MTF) was charged by then president David Lewis with assessing the current makeup of URM membership and developing ways, if needed, to attract and retain more URMs in the ACNP. Initial efforts in this regard found that URM participation and membership in the ACNP was distressingly low (see MTF Report at www.acnp.org). The report found that of 823 active members (including Associate, Full, and Fellow), only $0.8 \%$ identified as African American, 3.4\% as Hispanic/ Latino, and $0 \%$ Pacific Islander or Native Americans. In addition, between 2011 and 2014, URM membership in the college remained flat ( 3\%; see Figure 1). Of 224 Emeritus members, $0.9 \%$ identified as Hispanic and $0 \%$ from all the other subgroups (although 29\% did not report race/ ethnicity).

In addition, data from 2011 to 2014 indicated that of 218 past travel awardees, only 33 (15.1\%) were URMs. This low percentage may be partly attributable to significantly low numbers of URM applicants (only seven in 2013). In an effort to increase diversity, the ACNP established a Minority Travel Award in 1991 to facilitate the attendance and participation of URMs at its annual meetings. Recently, more concerted efforts were made, including sending letters to psychiatry and pharmacology chairs, and to NIH directors encouraging URMs to apply. Hearteningly, signs of progress

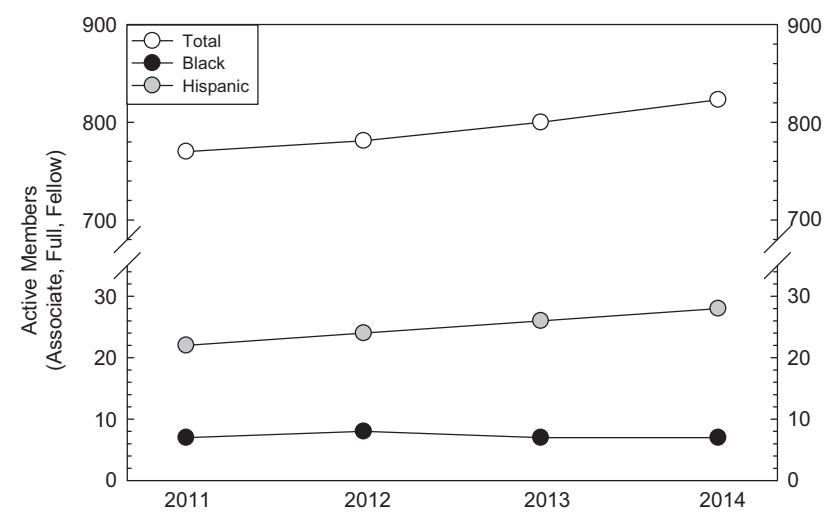

Figure I ACNP membership makeup (Associate, Full, and Fellow) for the years 201I-20l4 shown as total (open symbols), and by URM subgroups, including Hispanic (gray symbols) and Black (black symbols). Minority Task Force Report on initiatives at www.acnp.org. Data presented include women and men members combined. are starting to emerge. In 2014, 28 URM applications were received, and 12 of the $58(21 \%)$ travel awardees were URMs; in 2015, 44 of the 338 applications received were from URMs, and 9 of the 58 awards (15\%) went to URMs.

The MTF also investigated how many URM travel awardees went on to become members of the ANCP. We found that of 65 URM travel awardees between 2008 and 2014, only $2(3.1 \%)$ became Associate or Full members; in contrast, 31 of 257 (12.1\%) non-URM travel awardees became Associate or Full members. Although the reason for such disappointing numbers is unclear, it is possible that over a decade of slowdowns in federal research dollars combined with decreased likelihood of success in obtaining $\mathrm{NIH}$ grant funding (Ginther et al, 2011) may place URM scientists at an even greater disadvantage, thus taking them longer to build a successful application for membership. Nevertheless, these findings clearly suggest that we must engage in much more aggressive efforts to attract, recruit, and retain URMs in the ACNP. These efforts may include tracking URM travel awardees and providing mentorship as they progress in the field, making benchmarks toward membership more transparent, and helping navigate the 'unstated' rules for promotion within the college.

Though far from ideal, the current situation is not without hope. Specifically, the ACNP Council, working in conjunction with the MTF, has implemented new short- and longterm initiatives (see MTF Report at www.acnp.org) to increase URM representation and inclusion in the ACNP. Another bright spot is the increased number of accepted panels that include URMs. This was the result of a programmatic change made to the call for proposals that included women (42\%) and URMs (6\%) in the composition of these panels. Other initiatives include: releasing funds to past URM travel awardees with an invitation to attend the meeting for two additional years (pending adequate and continued progress in the field); the addition of a URM lunch - similar to the women's-to discuss issues related to increasing diversity and inclusion; the development of guidelines to facilitate mentorships that may go beyond an initial meeting; ongoing discussion of ways to increase URM representation in key committees in the ACNP; and the creation of an ACNP-sanctioned mentoring award to those members making a significant difference in promoting diversity and inclusion in science and within the college.

As noted at the beginning of this commentary, diversity in the sciences is crucial. But simply hoping to increase diversity in numbers without genuine commitment to a strategic plan that also involves inclusion is pointless. We are in a position to make a real difference in terms of offering young URMs the opportunity to be identified early, successfully mentored, and trained in the best programs. As with all eager young scientists, what they make of their opportunity is up to them. Most importantly, the efforts we make now to implement sustainable initiatives that will increase the diversity of the ACNP, so that it truly is a representative membership of high quality scientists will pave the way to a stronger future membership. In addition to the ability to track our progress, any such initiatives should also strive to create an atmosphere of warm and collaborative inclusion within the ACNP. It is in this spirit that we must lend genuine support to these initiatives for them to succeed. 


\section{FUNDING AND DISCLOSURE}

Dr Zarate is supported by the Intramural Research Program of the National Institute of Mental Health, National Institutes of Health (IRP-NIMH-NIH), by a NARSAD Independent Investigator Award, and by a Brain \& Behavior Mood Disorders Research Award. Dr Zarate is listed as a coinventor on a patent for the use of ketamine and its metabolites in major depression. Dr Zarate has assigned his rights in the patent to the US government, but will share a percentage of any royalties that may be received by the government. Dr CABG received funding from the National Institute on Drug Abuse, National Institutes of Health (NIDA-NIH).

\section{ACKNOWLEDGMENTS}

CAB-G currently serves as Chair of the Underrepresented MTF (2015-16) and is a member of the Program Committee for ACNP (2014-16). CAZ Jr served as Chair of the Underrepresented MTF (2014), and is Chair of the Program Committee for ACNP in 2016. We thank the ACNP staff, particularly Laura Hill and Sarah Timm, for assisting with data collection for the URM Task Force. Some information highlighted herein appeared in a previous report by URM Task Force members (Richard De La Garza III, Anthony Ahmed, Victoria Arango, CAB-G, Deborah Deas, Bankole Johnson, Gonzalo Laje, Francis Lotrich, Mauricio Tohen, and CAZ Jr).

\section{REFERENCES}

Bernstein R (2015). Barriers for Women of Color in Science. Available at: http://www.sciencemag.org/careers/2015/02/barrierswomen-color-science. Accessed 6 April 2016.

Change the Equation (2015). Solving the Diversity Dilemma: Changing the Face of the STEM Workforce. Available at: http:// changetheequation.org/sites/default/files/2015\%20Solving\%20the \%20Diversity\%20Dilemma\%20FINAL\%206.2015.pdf. Accessed 20 January 2016.

Deman D (2012). For Women Execs in Pharma, the Glass Ceiling is Cement. Available at: http://www.forbes.com/sites/ matthewherper/2012/04/13/guest-post-the-drug-industrys-cementceiling-for-women-execs/\#744fa59a7b8b. Accessed 6 April 2016.

Fang D, Moy E, Colburn L, Hurley J (2000). Racial and ethnic disparities in faculty promotion in academic medicine. JAMA 284: 1085-1092.
Ginther DK, Schaffer WT, Schnell J, Masimore B, Liu F, Haak LL et al (2011). Race, ethnicity, and NIH research awards. Science 333: 1015-1019.

Leadley J, Coakley E, Sloane RA (2012). Women in U.S. Academic Medicine and Science: Statistics and Benchmarking Report (2011-2012), AAMC 2012. Available at https://www.aamc. org/download/415556/data/2011-2012wimsstatsreport.pdf. www. aamc.org (accessed 20 January 2016).

McCook A (2013). Women in biotechnology: barred from the boardroom. Nature 495: 25-27.

Moghaddam B, Gur RE (2015). Women at the podium: ACNP strives to reach speaker gender equality and the annual meeting. Neuropsychopharmacology 41: 929-931.

National Institutes of Health (2012). Biomedical Workforce Working Group. Available at: http://acd.od.nih.gov/bmw_report.pdf. Accessed 20 January 2016.

National Research Council (2007). Rising Above the Gathering Storm: Energizing and Employing America for a Brighter Economic Future. National Academies Press: Washington DC, USA. Accessed 4 February 2016.

National Research Council (2011). Expanding Underrepresented Minority Participation. National Academy Press: Washington DC, USA. Accessed 20 January 2016.

National Science Foundation (2014). Science and Engineering Indicators. Available at: http://www.nsf.gov/statistics/seind14/ content/overview/overview.pdf. Accessed 4 February 2016.

National Science Foundation (2015). Women, Minorities, and Persons with Disabilities in Science and Engineering: 2015, Special Report NSF 13-304, Arlington, VA. Available at: http://www.nsf. gov/statistics/2015/nsf15311/. Accessed 28 January 2016.

Neuhauser A (2015). 2015 STEM Index Shows Gender, Racial Gaps Widen. Available at: http://www.usnews.com/news/stem-index/ articles/2015/06/29/gender-racial-gaps-widen-in-stem-fields?int = a77009. Accessed 15 December 2015.

Rodriguez JE, Campbell, Mouratidis RW (2014). Where are the rest of us? Improving representation of minority faculty in academic medicine. South Med J 107: 739-744.

Rodriguez JE, Campbell KM, Pololi LH (2015). Addressing disparities in academic medicine: what of the minority tax? BMC Med Educ 15: 6.

Sege R, Nykiel-Bub L, Selk S (2015). Sex differences in institutional support for junior biomedical researchers. JAMA 314: 1175-1177.

Tabak LA, Collins FS (2011). Weaving a richer tapestry in biomedical science. Science 333: 940-941.

Women Scientist Advisors Committee (2016). Available at: http://sigs.nih.gov/wsa/Pages/default.aspx. Accessed 5 April 2016. 